\title{
An ecological model of the artificial ecosystem (northern Hangzhou Bay, China): analysis of ecosystem structure and fishing impacts
}

\author{
Zuozhi Chen $\cdot$ Shannan Xu $\cdot$ Peimin He
}

Received: 2 December 2009/Revised: 20 June 2010/ Accepted: 14 July 2010/Published online: 1 August 2010

(C) Springer-Verlag and AWI 2010

\begin{abstract}
The artificial ecosystem is a large-scale enclosure in northern Hangzhou Bay, China. Using the Ecopath with Ecosim software, a trophic structure model is constructed for 2006-2007 to characterize the food web structure, functioning, and describing the ecosystem impacts of fishing. Input information for the model were gathered from published and unpublished reports and from our own estimates during the period 2006-2007. Pedigree work and simple sensitivity analysis were carried out to evaluate the quality and the uncertainty of the model. Results show that the food web in the enclosed sea area was dominated by a detritus pathway. The trophic levels of the groups varied from 1.00 for primary producers and detritus to 3.90 for piscivorous fish in the artificial system. Using network analysis, the system network was mapped into a linear food chain, and five discrete trophic levels were found with a mean transfer efficiency of $9.8 \%$ from detritus, $9.4 \%$ from primary producer within the ecosystem. The geometric mean of the trophic transfer efficiencies was $9.5 \%$. Detritus contributed $57 \%$ of the total energy
\end{abstract}

Communicated by H.-D. Franke.

Electronic supplementary material The online version of this article (doi:10.1007/s10152-010-0218-z) contains supplementary material, which is available to authorized users.

\section{Z. Chen $(\bowtie) \cdot S$. Xu}

Key Laboratory of Mariculture, Ecology and Quality Control, Ministry of Agriculture, South China Sea Fisheries Research Institute, Chinese Academy of Fishery Sciences,

No. 231 Xingang West Road, 510300 Guangzhou, China

e-mail: zzchen2000@163.com

P. He

College of Fisheries and Life Science,

Shanghai Ocean University, 201306 Shanghai, China flux, and the other $43 \%$ came from primary producers. The ecosystem maturity indices-TPP/TR (total primary production/total respiration), FCI (Finn cycling index), A (ascendancy) and TB/TDET were 2.672, 25\%, 31.5\%, and 0.013 , respectively, showing that the artificial system is at developmental stage according to Odum's theory of ecosystem development. The 'Keystoneness' result indicates that herbivorous zooplankton was identified as keystone species in this system. Furthermore, a simple dynamical simulation was preformed for varying fishing mortality over 10 years. The biomass of most fish groups has a small increase when the fishing mortality at current level. Increasing fishing mortality by twofold resulted in a marked decrease in biomass of piscivorous fish accompanied by an increase in that of other fish groups, notable zooplanktivorous fish. Generally, this study represents the first attempt to evaluate the food web structure and the potential effects of fisheries in the artificial coastal ecosystem. It is concluded that this model is a potential tool for use in the management of the artificial ecosystem in northern Hangzhou Bay.

Keywords Ecopath with Ecosim - Trophic structure . Network analysis · Fishing impact · Artificial ecosystem . Detritus pathway

\section{Introduction}

In recent years, the rapid growth in the human population and in activities such as various agricultural practices, industrial wastewater discharge, urban runoff, burning of fossil fuels and large-scale finfish and shrimp aquaculture has resulted in an increase of nutrient inputs compared to that generated by natural processes (De Jonge et al. 2002). 
Today, coastal waters of China are the primary recipients of nutrients from land and finfish and/or shrimp aquaculture, and many areas exhibit typical symptoms of eutrophication (Xu and $\mathrm{He}$ 2006). Rapid growth of intensive mariculture adds a continuous or pulsed release of nutrients, which contributes to coastal deterioration (Troell et al. 2003; Neori et al. 2004). Among different measures to improve the deterioration of coastal environments, seaweed cultivation has received greater attention worldwide, and especially in China, because of the low cost of cultivation and possible redundant nutrients pollutant removal by the seaweed (He et al. 2008).

The study area is located in Jinshan District, Shanghai. Shanghai Chemical Industry Park is located in the northeastern zone of Jinshan District in northern Hangzhou Bay; the SINOPEC Shanghai Petrochemical Company Limited is on the west zone. The coastal artificial ecosystem covers an area of (Fig. 1). The coastal sea area of Jinshan is particularly sensitive to the impact of human activities because of restricted exchange with the ocean (Shen et al. 2003). This has resulted in serious organic pollution and eutrophication in the bay. The water quality and environment of the system is seriously threatened by industrial wastewater and agricultural practices in surrounding areas. This suggests that eutrophic conditions occurred along all sites near the coastal areas (SOAC 2005).

The construction of the Jinshan artificial ecosystem that we studied was proposed as a part of the restoration plan developed by the Coastline Development Management Committee of Jinshan District (CDMCJS). To improve the water quality and transparency, the CDMCJS in April 2005 reclaimed some areas from the sea, constructed a seawall, and implemented measures such as sewage interception and physical settlement. Then, we used bioremediation techniques, such as seaweed cultivation and stock

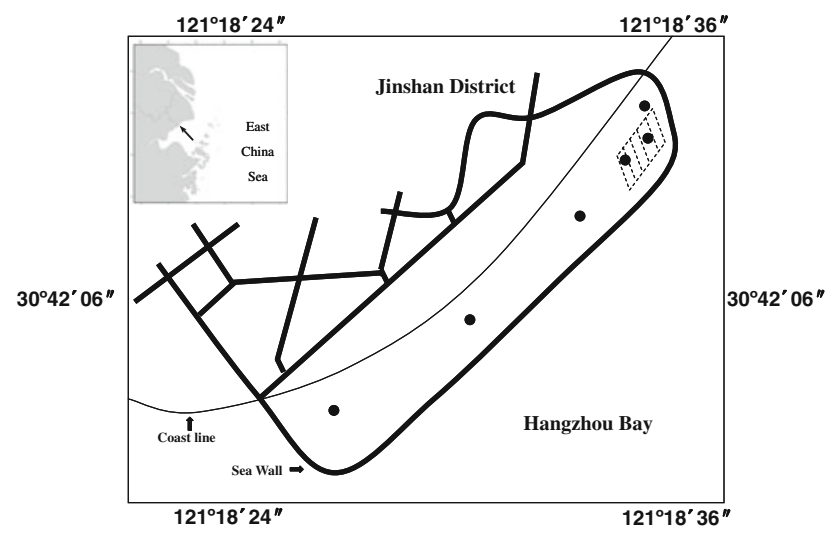

Fig. 1 Schematic map showing the artificial ecosystem of large-scale sea area enclosure in northern Hangzhou Bay. The dots represent sampling sites and the dotted polygons represent the seaweeds cultivation area enhancement in the artificial ecosystem on a large-scale enclosed sea area. In China, seaweed cultivation is receiving great attention because of the low cost involved and its higher capability to rapidly assimilate nitrogen and phosphorous nutrients (Xu and $\mathrm{He} 2006$ ). The cultivation area of macrophytes was confined to the northeastern part of the artificial system (Fig. 1) to avoid any damage to tourism. After the completion of physical engineering requirements in 2005, we cultivated 9,700 kg Gracilaria verrucosa and $500 \mathrm{~kg}$ Ulva clathrata in the system. Since then, to integrate and improve the service function of the system, we have enhanced and cultured fish, shrimp, crab, and shellfish according to their biological characteristic in the system. The rationale is that fish species in an ideal polyculture pond occupy different niches and possess feeding habits which are different from and complementary to each other, therefore, are able to utilize food available in the pond more efficiently than single species (Yuan et al. 2010). In the coastal artificial system, the fishes include 6,000 Pseudosciaena crocea with body length (BL) ranging from 140 to $150 \mathrm{~mm}$; 2,000 Sparus macrocephalus, BL range, $65-70 \mathrm{~mm}$; and 10,000 Mugil cephalus and Liza haematocheila, $\mathrm{BL}$ range, $10-15 \mathrm{~mm}$. The invertebrates include $700 \mathrm{~kg}$ of Exopalaemon carinicauda with shell length (SL) ranging from 5 to $50 \mathrm{~mm} ; 2.4 \times 10^{5}$ Metapenaeus ensis with SL range of $6-8 \mathrm{~mm}, 100 \mathrm{~kg}$ of Portunus trituberculatus with carapace length ranging from 20 to $40 \mathrm{~mm}$. Additionally, we increased the number and size of various macro-benthos, including Crassostrea gigas, Mactra veneriformis, Ruditapes philippinarum, Tegillarca granosa, and Thais clavigera. In the coastal artificial system, the phytoplankton species mainly consists of diatoms and dinoflagellates which occupy $96.9 \%$ of the total, but the species of Chrysophyta, Cyanophyta, and Chlorophyta is few, and the dominant zooplankton species was Copepoda (Labidocera euchaeta, Calanus sinicus, Paracalanus paruus), Mysidacea, Sagitta sp., Acetes chinensis in 2004. As a result, water quality of the artificial ecosystem has significantly improved from class IV in 2004 to class II (Xu 2008), following the Chinese national standard after bioremediation (SEPAC 2002). As a consequence, chemical contamination in the water column decreased significantly, and transparency of sea water increased from 1.5-2 to 5.5-6.0 $\mathrm{m}$ also (Xu 2008). Now, the artificial ecosystem in northern Hangzhou Bay is of great importance for tourism, recreational, and aquaculture purposes.

To our knowledge, measurements of the flow, efficiency of assimilation, transfer and dissipation of material and energy among the various ecosystem components can provide significant information on the fundamental structure and function of the whole ecosystem (Baird and Ulanowicz 1989; Christian et al. 1996). Until now, most of energy flow and property studies are focus on natural 
ecosystems; however, studies on artificial coastal ecosystems are relatively sparse (Wolff 1994; Dalsgaard and Oficial 1997; Lin et al. 2004; Li et al. 2007).

Mass-balance models are being used globally as an efficient and useful method to systematically describe ecosystems and to explore their properties (Christensen 1995). EwE is a useful tool to investigate effects of the biological community changes induced by external sources of disturbance on the ecosystem structure. The prominent advantage of this approach lies in its suitability to the application of a broad field of theories that are useful for ecosystem studies, which includes thermodynamic concepts, information theory, trophic level description and network analysis (Christensen et al. 2000). In this case study of an artificial ecosystem, a mass-balanced steadystate model is constructed using ECOPATH approach for the large-scale enclosure in northern Hangzhou Bay. The objectives of this study were (1) to present a model of the trophic interactions within a coastal artificial ecosystem; (2) to determine the key trophic pathways and keystone species in the system; and (3) to describe quantitatively the characteristics of the system as a whole and the possible impact of harvesting strategies on its components.

\section{Materials and methods}

\section{Study site}

The artificial ecosystem is a large-scale enclosure area of a sandy beach in northern Hangzhou Bay $\left(30^{\circ} 42^{\prime} \mathrm{N}\right.$, $121^{\circ} 18^{\prime} \mathrm{E}$ ), covering about $1.6 \mathrm{~km}^{2}$ of surface area (Fig. 1). It has a subtropical monsoon climate, with water temperatures ranging from about $35^{\circ} \mathrm{C}$ in July to about $5^{\circ} \mathrm{C}$ in January. Annual mean precipitation varies between 988.1 and $1,197.2 \mathrm{~mm}$ (Shen et al. 2003). The large-scale enclosure sea area has a coastline of $3.16 \mathrm{~km}$ and average depth of the lagoon is approximately $5 \mathrm{~m}$. The reclaimed sea wall is $3,625 \mathrm{~m}$ in length, and the average distance from the coastline to the sea wall is $500 \mathrm{~m}$. The cultivation area of macrophytes was confined to the northeastern part of the artificial system (Fig. 1) to avoid any damage to tourism.

\section{Ecopath modeling approach}

Ecopath is an approach that models the average interactions of the populations within an ecosystem during a defined period. The model is based on mass-balance principles, assuming that the production of a given ecological group is equal to the biomass lost to fishing or export, predation and natural mortality other than predation (other mortality) (Christensen et al. 2000). It is expressed by the mass-balance equation:

$P_{i}-B_{i} M 2_{i}-P_{i}\left(1-\mathrm{EE}_{i}\right)-\mathrm{EX}_{i}=0$

where $P_{i}$ is the production of group $i, B_{i}$ is biomass in tons (wet weight), $M 2_{i}$ is mortality by predation. $E_{i}$ is the net migration (emigration-immigration), while $P_{i}\left(1-\mathrm{EE}_{i}\right)$ is the 'other mortality'. $\mathrm{EE}_{i}$ is the 'ecotrophic efficiency', i.e., the proportion of the production of $i$ that is exported or consumed by the predators in the system. The first term represents production, the second represents losses by predation, the third represents losses that are not assigned to predation or export, and the last term represents losses by export. The equation is equal to zero because it is at equilibrium.

Because material transfers between groups are achieved through trophic relationships, Eq. 1 is rewritten as

$B_{i}\left(\frac{P}{B}\right)_{i}-\sum_{j=1}^{n} B_{j}\left(\frac{Q}{B}\right)_{j} \mathrm{DC}_{j i}-B_{i}\left(\frac{P}{B}\right)_{i}\left(1-\mathrm{EE}_{i}\right)-\mathrm{EX}_{i}=0$

where subscript $j$ represents predators, $B_{j}$ is predator biomass in tons wet weight, $P / B$ is production to biomass ratio, which is equal to the coefficient of total mortality $Z$ under steady-state conditions (Allen 1971). $\mathrm{EE}_{i}$ and $\mathrm{EX}_{i}$ are the same terms used in Eq. $1, Q / B_{j}$ is consumption to biomass ratio of predator $j$. $\mathrm{DC}_{j i}$ is the contribution of prey $i$ in the diet of predator $j$. Each group was represented by a similar equation, and a system of linear equation was established in which at least three of the four parameters $(B, P / B, Q / B$, and EE) of each group were known and only one was estimated by the model, if needed. In summary, Eq. 2 describes the biomass flow balance between the inputs and the outputs of each group.

Ecopath model parameterization

The model of artificial ecosystem comprised 13 functional groups consisting of 4 fish groups, 4 invertebrate groups, 2 groups of zooplankton (herbivorous and carnivorous zooplankton), 2 groups of primary producers (phytoplankton and macrophytes), and a detritus group (Table 1). Most groups were composite groups that included species of similar diets, trophic positions, and life histories. Biomass was expressed in tons wet weight (WW) $\mathrm{km}^{-2}$ and production and other flow were expressed in tons wet weight (WW) $\mathrm{km}^{-2}$ year $^{-1}$. For all functional groups, the key input data includes biomass $\left(B_{i}\right)$, production/biomass ratio $\left(P_{i} / B_{i}\right)$, consumption/biomass ratio $\left(Q_{i} / B_{i}\right)$, ecotrophic efficiency $\left(\mathrm{EE}_{i}\right)$, food composition $\left(\mathrm{DC}_{j i}\right)$, and fishing mortality $\left(F_{i}\right)$. Most of the input data used in the model were collected from survey during September 2006-June 
2007 (Xu 2008), peer-reviewed journal publications, and government reports as well (see detail in Table 1). Our own survey was conducted quarterly (in September and December of 2006, March and June of 2007) on six sampling sites (Fig. 1).

The detritus biomass was calculated as a function of primary production and euphotic depth by employing the relationship suggested by Christensen and Pauly (1993).

$\log ^{D}=-2.41+0.954 \log ^{\mathrm{PP}}+0.863 \log ^{E}$

where $D$ is the standing stock of detritus, in $\mathrm{gC} \mathrm{m}^{-2}$, $\mathrm{PP}$ the primary production in $\mathrm{gC} \mathrm{m}^{-2}$ year $^{-1}$ and $E$ is the euphotic depth in meters $(=5 \mathrm{~m})$.

Phytoplankton biomass in terms of chlorophyll A was measured using a Turner fluorometer according to standard procedures (Parsons et al. 1984). The lowest chlorophyll a concentration observed was $0.28 \mathrm{mg} \mathrm{m}^{-3}$ in February, 2006 while the highest $1.43 \mathrm{mg} \mathrm{m}^{-3}$ in July, 2007, so the average value of $0.850 \mathrm{mg} \mathrm{m}^{-3}$ during the model time. Phytoplankton biomass was estimated to be $2.832 \mathrm{~g} \mathrm{~m}^{-3}$ using the conversion factor of $0.3 \mathrm{mg}$ chlorophyll a per $100 \mathrm{mg}$ phytoplankton (Zhang and He 1991). Using a mean depth of $5 \mathrm{~m}$, we estimated the phytoplankton biomass of $14.16 \mathrm{~g} \mathrm{~m}^{-2}$. Macrophytes were collected by gently scraping them off the seawall with a blade around the area. The biomass of macrophytes in terms of wet weight was estimated according to Erftemeijer et al. (1993). Zooplankton samples were collected by openingclosing bongo nets (with a diameter of $37 \mathrm{~cm}$ and a mesh size of $0.03 \mathrm{~mm}$ ) through the water column. Biomass of zooplankton was estimated by displaced volume according to Ahlstrom and Thrailkill (1960). Herbivorous zooplankton included Moina micrura, Mysidacea larvae, Alima, and others. The dominant species of carnivorous zooplankton included Copepoda (Labidocera euchaeta, Calanus sinicus) and Chaetognatha (Sagitta bedoti, Sagitta regularis). In the artificial ecosystem, the biomass of herbivorous zooplankton and carnivorous zooplankton were 14.80 and $6.00 \mathrm{t} \mathrm{km}^{-2}$, respectively (Xu 2008).

Samples of infauna were collected quarterly (in March and June of 2007, September and December of 2006) from six sampling stations (Fig. 1) using a modified Peterson's grab sampler with an area of $0.0625 \mathrm{~m}^{2}$. Biomass of infauna varied between 0.972 and $27.328 \mathrm{t} \mathrm{km}^{-2}$, with an average value of $14.15 \mathrm{t} \mathrm{km}^{-2}$ in the system.

The biomass of fishes, shrimps, crabs, and molluscs were assessed by mobile acoustic instrument Simrad EK60 during 2006-2007 (Xu 2008). The biomass of targets $(B)$ from the observed echo integrals were estimated according to the equation $B=(K /\langle\sigma\rangle) E$, where $K$ is the calibration factor, $\langle\sigma\rangle$ is the mean cross-section and $E$ is the echo integral after partitioning (MacLennan and Simmonds 1992).

The consumption/biomass $(Q / B)$ ratio represents the amount of food ingested by a group with respect to its own biomass in a given period. Data of $Q / B$ for fish were computed with an empirical model developed by Palomares and Pauly (1998).

Table 1 Sources of input data values and literatures of Ecopath model of large-scale sea area enclosure in northern Hangzhou Bay

\begin{tabular}{|c|c|c|c|c|}
\hline Groups name & $B_{i}\left(\mathrm{t} \mathrm{km}^{-2}\right)$ & $P_{i} / B_{i}\left(\right.$ year $\left.^{-1}\right)$ & $Q_{i} / B_{i}\left(\right.$ year $\left.^{-1}\right)$ & Source (or derived from) \\
\hline 1 Phytoplankton & $14.16^{\mathrm{a}}$ & $118.20^{\mathrm{b}}$ & - & Own estimated based on Parson et al. $(1984)^{\mathrm{a}}$; Liu et al. $(2001)^{\mathrm{b}}$ \\
\hline 2 Macrophytes & $32.60^{\mathrm{a}}$ & $7.50^{\mathrm{b}}$ & - & Own estimate $^{\mathrm{a}} ;$ Vega-Cendejas $(2003)^{\mathrm{b}}$ \\
\hline 3 Herbivorous zooplankton & $14.80^{\mathrm{a}}$ & $86.00^{\mathrm{b}}$ & $280.00^{\mathrm{b}}$ & Own estimate $^{\mathrm{a}} ;$ Vega-Cendejas $(2003)^{\mathrm{b}}$ \\
\hline 4 Carnivorous zooplankton & $6.00^{\mathrm{a}}$ & $25.00^{\mathrm{b}}$ & $89.00^{\mathrm{b}}$ & Own estimate $^{\mathrm{a}}$; Vega-Cendejas $(2003)^{\mathrm{b}}$ \\
\hline 5 Infauna & $14.15^{\mathrm{a}}$ & $4.00^{\mathrm{b}}$ & $20.00^{\mathrm{b}}$ & Own estimate $^{\text {a }}$, Lin et al. $(1999)^{\mathrm{b}}$ \\
\hline 6 Mollusca & $6.82^{\mathrm{a}}$ & $1.75^{\mathrm{b}}$ & $14.00^{\mathrm{b}}$ & Own estimate $^{\mathrm{a}}$; Tong et al. $(2000)^{\mathrm{b}}$ \\
\hline 7 Shrimps & $3.15^{\mathrm{a}}$ & $1.84^{\mathrm{b}}$ & $24.40^{\mathrm{b}}$ & Own estimate $^{\mathrm{a}}$; Tong et al. $(2000)^{\mathrm{b}}$ \\
\hline 8 Crabs & $1.50^{\mathrm{a}}$ & $2.12^{\mathrm{b}}$ & $8.48^{\mathrm{b}}$ & 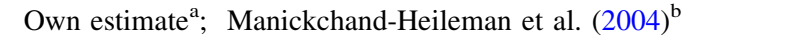 \\
\hline 9 Herbivorous fish & $1.21^{\mathrm{a}}$ & $1.32^{\mathrm{b}}$ & $12.00^{\mathrm{c}}$ & $\begin{array}{l}\text { Own estimate }{ }^{\mathrm{a}} \text {; based on Fishbase (Froese and Pauly 2004) } \\
\text { estimated by empirical formula (Palomares and Pauly 1998) }\end{array}$ \\
\hline 10 Zooplanktivorous fish & $1.25^{\mathrm{a}}$ & $1.28^{\mathrm{b}}$ & $7.50^{\mathrm{c}}$ & $\begin{array}{l}\text { Own estimate }{ }^{\mathrm{a}} \text {; based on Fishbase (Froese and Pauly 2004) } \\
\text { estimated by empirical formula (Palomares and Pauly 1998) }\end{array}$ \\
\hline 11 Benthic-feeding fish & $1.21^{\mathrm{a}}$ & $1.22^{\mathrm{b}}$ & $5.89^{\mathrm{c}}$ & $\begin{array}{l}\text { Own estimate }{ }^{\mathrm{a}} \text {; based on Fishbase (Froese and Pauly 2004) }{ }^{\mathrm{b}} \text {; } \\
\text { estimated by empirical formula (Palomares and Pauly 1998) }\end{array}$ \\
\hline 12 Piscivorous fish & $0.41^{\mathrm{a}}$ & $0.90^{\mathrm{b}}$ & $6.00^{\mathrm{c}}$ & $\begin{array}{l}\text { Own estimate }{ }^{\mathrm{a}} \text {; based on Fishbase (Froese and Pauly 2004) }{ }^{\mathrm{b}} \text {; } \\
\text { estimated by empirical formula (Palomares and Pauly 1998) }\end{array}$ \\
\hline 13 Detritus & $10.00^{\mathrm{a}}$ & - & - & Estimated by empirical formula (Christensen and Pauly 1993) ${ }^{a}$ \\
\hline
\end{tabular}

\footnotetext{
${ }^{a}$ Input parameters from own estimate

b, c Input parameters from literatures
} 


$$
\begin{aligned}
\log (Q / B)= & 7.964-0.204 \log W_{\infty}-1.965 T^{\prime}+0.083 A \\
& +0.532 h+0.398 d
\end{aligned}
$$

where $W_{\infty}$ is the asymptotic weight (g) from the VGBF, $T^{\prime}$ is an expression for the mean annual temperature of the water body, expressed using $T^{\prime}=1,000 \mathrm{~K}^{-1}\left(K={ }^{\circ} \mathrm{C}+273\right)$. $A$ is the aspect ratio, calculated using $A=h^{2} / s$, where $h$ the height of caudal fin and $s$ its surface area (Christensen et al. 2000 ), and $h$ is the dummy variable expressing food type ( 1 for detritivores and 0 for herbivores and carnivores).

The production/biomass $(P / B)$ values of fish are equivalent to the instantaneous rate of total mortality $(Z)$, see Allen (1971), which was estimated by the method of Beverton and Holt (1957) and calculated using the FiSAT II (Gayanilo et al. 1996).

$Z=\frac{K\left(L_{\infty}-\bar{L}\right)}{\bar{L}-L^{\prime}}$

where $L$ is the asymptotic length $(\mathrm{cm}), K$ is the VBGF curvature parameter, $\bar{L}$ is the mean length in the population (cm), $L^{\prime}$ represents the mean length at entry into the fishery (cm). Data of $P / B$ for fishes were taken from Fishbase (Froese and Pauly 2004). For those group whose $Q / B$ and $P / B$ were difficult to estimate, were obtained from similar ecosystem models, which are located in the studied area or near the studied area (Vega-Cendejas 2003; Tong et al. 2000; Lin et al. 1999; Manickchand-Heileman et al. 2004).

Data on landing statistics of various fishes, invertebrates and macrophytes were taken from the CDMCJS statistics (unpublished data, see Table 2). Samples were taken to measure body weight and body length (to the nearest half centimeter), stomach analysis and scales were taken for age determination.
$\mathrm{DC}_{j i}$ is the fraction that prey group $i$ contributes to the overall stomach contents of predator group $j$ (Christensen et al. 2000). As a predation index in the Ecopath model, $\mathrm{DC}_{j i}$ links the different groups together and reveals the dynamics within the ecosystems. This fraction can be measured in weight percentage, volume percentage, occurrence percentage or even energy content percentage. For this model, the diets of fishes were measured in weight percentage based on the stomach contents analysis. For those groups whose quantitative diet information was often unavailable, the parameter values were obtained from similar ecosystem models or published literature (VegaCendejas 2003; Tong et al. 2000; Lin et al. 1999; Manickchand-Heileman et al. 2004). Diet compositions were summarized in Table 3.

Ecosystem maturity, structure, and flow analysis

Ecopath can calculate a number of indices to assess the stability and maturity of the ecosystem (Odum 1969) and to make comparisons among ecosystems. It also gives a number of network flow indices based on concepts developed by theoretical ecologists, notably Ulanowicz (1986). The total system throughput is the sum of all flows in the system, estimated as the sum of the four flow components: (1) sum of all consumption; (2) sum of all exports; i.e., exported from the system by fisheries or buried in the sediments; (3) sum of all respiration flows; and (4) sum of all flows into detritus. The total system throughput represents the size of the system in terms of flows (Ulanowicz 1986) and is important for comparisons of flow networks.

\begin{tabular}{|c|c|c|c|c|c|c|c|c|}
\hline Trophic group & $\begin{array}{l}\text { Biomass } \\
\left(\mathrm{t} \mathrm{km}^{-2}\right)\end{array}$ & $P / B\left(\right.$ year $\left.^{-1}\right)$ & $Q / B\left(\right.$ year $\left.^{-1}\right)$ & EE & GE $(P / Q)$ & Trophic level & $\begin{array}{l}\text { Unassimilated } \\
\text { consumption }\end{array}$ & $\begin{array}{l}\text { Catch } \\
\left(\mathrm{t} \mathrm{km}^{-2}\right)\end{array}$ \\
\hline 1 Phytoplankton & 14.16 & 118.2 & - & 0.194 & - & 1.00 & 0.4 & - \\
\hline 2 Macrophytes & 32.60 & 7.50 & - & 0.591 & - & 1.00 & 0.4 & 2.52 \\
\hline 3 Herbivorous zooplankton & 14.80 & 86.00 & 280.00 & 0.358 & 0.307 & 2.00 & 0.4 & - \\
\hline 4 Carnivorous zooplankton & 6.00 & 25.00 & 89.00 & 0.891 & 0.281 & 2.84 & 0.3 & - \\
\hline 5 Infauna & 14.15 & 4.00 & 20.00 & 0.902 & 0.200 & 2.44 & 0.3 & - \\
\hline 6 Mollusca & 6.82 & 1.75 & 14.00 & 0.376 & 0.125 & 3.05 & 0.2 & - \\
\hline 7 Shrimps & 3.15 & 1.84 & 24.4 & 0.307 & 0.075 & 2.96 & 0.2 & - \\
\hline 8 Crabs & 1.50 & 2.12 & 8.48 & 0.492 & 0.174 & 3.23 & 0.2 & - \\
\hline 9 Herbivorous fish & 2.21 & 1.32 & 12.00 & 0.553 & 0.110 & 2.09 & 0.2 & 0.40 \\
\hline 10 Zooplanktivorous fish & 1.25 & 1.28 & 7.50 & 0.779 & 0.171 & 3.14 & 0.2 & 0.25 \\
\hline 11 Benthic-feeding fish & 1.21 & 1.22 & 5.89 & 0.501 & 0.207 & 3.22 & 0.2 & 0.08 \\
\hline 12 Piscivorous fish & 0.41 & 0.90 & 6.00 & 0.407 & 0.150 & 3.90 & 0.2 & 0.15 \\
\hline 13 Detritus & 10.00 & - & - & 0.440 & - & 1.00 & & - \\
\hline
\end{tabular}

Table 2 The basic input data and biological parameters of groups as estimated by Ecopath for the artificial ecosystem model

Values in italic were estimated by model 
Table 3 Diet composition matrix, in percentage of volume of prey groups, assembled from research data to construct the artificial ecosystem model

\begin{tabular}{|c|c|c|c|c|c|c|c|c|c|c|}
\hline Prey/predator & 4 & 5 & 6 & 7 & 8 & 9 & 10 & 11 & 12 & 13 \\
\hline 1 Phytoplankton & 0.10 & & 0.15 & 0.10 & & & 0.53 & & & \\
\hline 2 Macrophytes & & & & & & & 0.17 & & & \\
\hline 3 Herbivorous zooplankton ${ }^{a}$ & 0.30 & 0.75 & 0.11 & 0.12 & 0.10 & 0.07 & 0.09 & 0.20 & & \\
\hline 4 Carnivorous zooplankton ${ }^{\mathrm{a}}$ & & 0.05 & 0.13 & 0.35 & 0.35 & 0.35 & & 0.45 & 0.01 & \\
\hline 5 Infauna $^{\mathrm{b}}$ & & & 0.06 & 0.20 & 0.15 & 0.12 & & & 0.23 & \\
\hline 6 Mollusca $^{\mathrm{c}}$ & & & & & & 0.16 & & & 0.10 & \\
\hline 7 Shrimp $^{c}$ & & & & & & & & 0.02 & 0.19 & \\
\hline $8 \mathrm{Crabs}^{\mathrm{d}}$ & & & & & & & & 0.02 & 0.20 & \\
\hline 9 Herbivorous fish $^{\mathrm{e}}$ & & & & & & & & & 0.03 & 0.252 \\
\hline 10 Zooplanktivorous fish ${ }^{\mathrm{e}}$ & & & & & & & & 0.01 & & 0.448 \\
\hline 11 Benthic-feeding fish ${ }^{\mathrm{e}}$ & & & & & & & & & & 0.30 \\
\hline \multicolumn{11}{|l|}{12 Piscivorous fish ${ }^{\mathrm{e}}$} \\
\hline 13 Detritus & 0.60 & 0.2 & 0.55 & 0.23 & 0.40 & 0.30 & 0.21 & 0.30 & 0.24 & \\
\hline
\end{tabular}

${ }^{a}$ Lin et al. (1999)

b Vera-Cendejas (2003)

c Tong et al. (2000)

${ }^{d}$ Manickchand-Heileman et al. (2004)

e Based on content analysis

Total net primary production is the sum of production by all the producers (i.e., phytoplankton and macrophytes) in the system. The ratio total primary production/total respiration describes the maturity of the system (Odum 1971) where mature systems have a ratio of 1 . Production normally exceeds respiration in early phases of development, while the opposite occurs in organically polluted ecosystems (Christensen and Pauly 1993). The sum of all production is the sum of the primary and secondary production in the ecosystem. The total biomass/total throughput ratio is used to assess the total biomass supported by the available energy and is expected to increase with ecosystem maturity. The connectance index (CI) and the system omnivory index (SOI) are correlated with system maturity, since a food chain is expected to change from linear to web-like as the system matures (Odum 1971; Christensen et al. 2000). The degree of recycling in a system can be measured with Finn's cycling index (FCI) and Finn's mean path length (FML). The FCI represents the proportion of the total throughput that is devoted to recycling of material. The FML, the average number of groups that an inflow or outflow passed through (Finn 1976), is strongly correlated with the FCI. 'Mature' and 'stable' systems generally display a high degree of recycling (Christensen 1995). The ratio of total biomass to total flows into detritus (TB/ TDET), which indicates how much of the energy is transformed into organic material, is used as new attribute in this study. This ratio increases as the system matures. If this ratio is close to 1 , all the organisms will be recycling rapidly and the system will have reached a mature state. If the rate differs from 1 , the ecosystem is still developing.

One of the model outputs is the fractional or effective trophic level of each group (Odum and Heald 1975). The trophic level of fishery catch $\left(\mathrm{TL}_{C}\right)$ which resulted from the suggested fishing effort in each strategy was calculated using:

$\mathrm{TL}_{C}=\left[1 /\left(C_{t}\right)\right] * \Sigma\left(C_{i} * \mathrm{TL}_{i}\right)$,

where, $\Sigma C_{i}=C_{t}, C_{t}$ is the total catch, while $C_{i}$ is the catch of stock $i$, and $\mathrm{TL}_{i}=$ the mean trophic level of the stock $i$.

Although the system is assumed to be in a steady state, it is possible to determine the expected response of each group in the model to perturbations in this steady state by introducing minute increases in biomasses of each group. Overall positive and negative impacts of such increases of each group on the others through direct and indirect routes were evaluated using the mixed trophic impact analysis, which is carried out by Ecopath using the Leontief (1951) matrix routine as developed by Ulanowicz and Puccia (1990). The MTI analysis reflected interactions among groups, with the value ranging from -1 to 1 . If the two groups mutually benefited from each other, the MTI had a value greater than 0 . Otherwise, the MTI had a negative value. Moreover, a method derived from the MTI analysis allows estimating 'keystoneness' of groups and identifying the keystone species in the ecosystem. The keystoneness value of a given species is decided as a function of its biomass and the impact on the different elements of an 
ecosystem resulting from a small change to its own biomass. It can be implemented by plotting the relative overall effect $\left(\varepsilon_{i}\right)$ against the keystoneness $\left(\mathrm{KS}_{i}\right)$. Here, the overall effect of each group is defined as (Libralato et al. 2006):

$\varepsilon_{i}=\sqrt{\sum_{j \neq i}^{n} m_{i j}^{2}}$

where $m_{i j}$ is obtained from the MTI analysis as the product of all the net impacts for all the possible pathways in the food web linking functional groups $i$ and $j$. The relative overall effect $\left(\varepsilon_{i}\right)$ is expressed to be relative to the maximum effect measured in the trophic web.

In Eq. 7, the effect of the change in biomass on the group itself (i.e., $\left.m_{i j}\right)$ is excluded. The keystoneness $\left(\mathrm{KS}_{i}\right)$ of each group is described as (Libralato et al. 2006):

$\mathrm{KS}_{i}=\log \left[\varepsilon_{i} \times\left(1-p_{i}\right)\right]$

where $p_{i}$ is the contribution of the functional group to the total biomass of the food web.

\section{Modification strategy of input values}

One of the most important steps in modeling is to verify whether a model yields a biologically realistic outcome and if it conforms to observed data. For the Ecopath model, the first attempt in balancing the model is often done by evaluating if the ecotrophic efficiency (EE) estimated in modeling for each group is less than 1. It is inevitable for the EEs of some groups to have values greater than 1 in the first modeling iteration when the initial inputs are used. When unbalanced groups were encountered in modeling, we used the 'automatic massbalance' function built in the Ecopath model to re-evaluate and modify parameters to achieve the goal of having EE smaller than 1 for all groups. Furthermore, we had to check if the GE (the gross food conversion efficiency, i.e., the ratio between production and assimilated food) was in the range of $0.1-0.3$, as the consumption of most groups is about 3-10 times higher than their production. Finally, the output values were compared with independent field measurements and literature data on other related coastal water.

\section{Simulation of impacts of varying fishing mortality}

The balance model was used to explore the possible impacts of varying fishing mortality on the biomass of the major groups. Various fishing scenarios were simulated by the Ecosim routine (Walters et al. 1997, 2000), and the resulting biomass change in each group was evaluated. Ecosim is a time dynamic simulation model that uses the linear equations of the static Ecopath model to isolate the biomass accumulation term, and set up a series of differential equations in the form of:

$\frac{\mathrm{d} B_{i}}{\mathrm{~d} t}=g i \sum_{j} C_{j i}-\sum_{j} C_{i j}+I_{i}-\left(M_{i}+F_{i}+e_{i}\right) B_{i}$

where $\mathrm{d} B_{i} / \mathrm{d} t$ is the biomass growth rate, $g_{i}$ is the net growth efficiency (production/consumption ratio), $C_{j i}$ is the total consumption rate of the group $i, C_{i j}$ is the predation of all predators on the group $i, M_{i}$ is the non-predation natural mortality rate, $F_{i}$ is the fishing mortality rate, $e_{i}$ is the emigration rate, and $I_{i}$ is the immigration rate.

This leads to the predictions of how biomass develops over time as a consequence of changes in fishing patterns or other ecosystem forcing functions. Ecosim requires a vulnerability setting for all predator-prey interactions. The setting controls the rate that a prey group moves between the vulnerable state and the state in which the group is not susceptible to predation by a given predator. The default setting is a mixture of top-down and bottom-up control (a setting of 1 for bottom-up control, $\gg 1$ for top-down control in the new EwE version 6.0). In this study, to realistically simulate bottom-up donor control and top-down predator control in the ecosystem trophic, the vulnerability of each functional group was set proportional (Table 2) to its trophic level estimated by Ecopath (Buchary et al. 2003; Chen et al. 2008). All others settings in Ecosim assumed default values. The two simple scenario sets were examined over a simulation length of 10 years.

Scenario 1 Keep the fishing mortality at current level as suggested by official statistics-i.e., fishing effort for the capture $0.40,0.25,0.08$, and $0.15 \mathrm{t} \mathrm{km}^{-2}$ year ${ }^{-1}$ for herbivorous fish, zooplanktivorous fish, benthic-feeding fish, and piscivorous fish, respectively.

Scenario 2 Fishing mortality increased twofold of the current fishing mortality.

Uncertainty and sensitivity analyses

Uncertainties of input parameters were specified under a 'pedigree' in the Ecopath with Ecosim package. The 'pedigree index' was calculated to quantify the uncertainty related to the input values in the model (Christensen and Walters 2004). For each input value, a description was made of the data and their confidence level (sample-based, high or low precision, approximate or indirect method, or from other models, from literature, etc.). Percent ranges of uncertainty, based on a set of qualitative choices relative to the origin of $B, P / B, Q / B$, and diet input or model estimates, were used in the routine and resulted in an index value scaled from 0 (data not rooted in local data) to 1 (data fully rooted in local data) for each input parameters. Based on the 
individual pedigree index value, an overall 'pedigree index' $P$ of the information in ECOPATH can be calculated:

$P=\sum_{i=1}^{n} \sum_{j=1} \frac{I_{i j}}{n}$

where $I_{i j}$ is the pedigree index for model group $i$ and parameter $j$ and $\mathrm{n}$ is the total number of modeled groups (Christensen and Walters 2004).

With the uncertainty in the input parameters, a simple sensitivity analysis was also conducted to evaluate the robustness of the results were with respect to uncertainty in input parameters. All basic input parameters were changed, independently, in steps of $10 \%$, from -50 to $+50 \%$. The effects of these changes on all the missing basic parameters for all groups in the system were examined. The impact of this on the estimated parameters is calculated as:

Estimated parameter - original parameter original parameter

\section{Results}

Trophic structure

A balanced model was successfully constructed for the artificial ecosystem (Table 2). In general, EE values were relatively low, most groups were in the range of $0.30-0.60$, however, EE was highest EE (0. 902) for infauna, followed by carnivorous zooplankton (0.891) and zooplanktivorous fish. Trophic levels (TLs) were estimated by the Ecopath from the weighted average trophic levels of each prey. The routine assigns a TL of 1 to primary producers and detritus, and TL of $1+$ (weighted average of the prey's TL) to consumers. The highest fractional trophic levels in the artificial system are occupied by piscivorous fish (Fig. 2; Table 2). The trophic aggregation routine in Ecopath aggregated the 13 groups with five effective TLs of Hangzhou Bay (Table 4). Primary producers (trophic level I) comprised the phytoplankton, macrophytes, and detritus. The detritus pool was a food source of many functional groups in the system. The most prominent biological group, in terms of biomass and energy flow in the system, was the herbivorous zooplankton. A large proportion $(>75 \%)$ of matter at trophic level II flows through herbivorous zooplankton, infauna, and herbivorous fish, whereas $88 \%$ of the flow of carnivorous zooplankton occurred at trophic level III. Less than half the flows of fish groups occurred at IV and V. The main harvestable target species in the system was macrophytes (Gracilaria verru$\cos a)$; the biomass was about $32.6 \mathrm{t} \mathrm{km}^{-2}$, the fishery yield, however, was $2.52 \mathrm{t} \mathrm{km}^{-2}$ (Table 2). Herbivorous fish alone accounted for $43.5 \%$ of the total fish biomass and

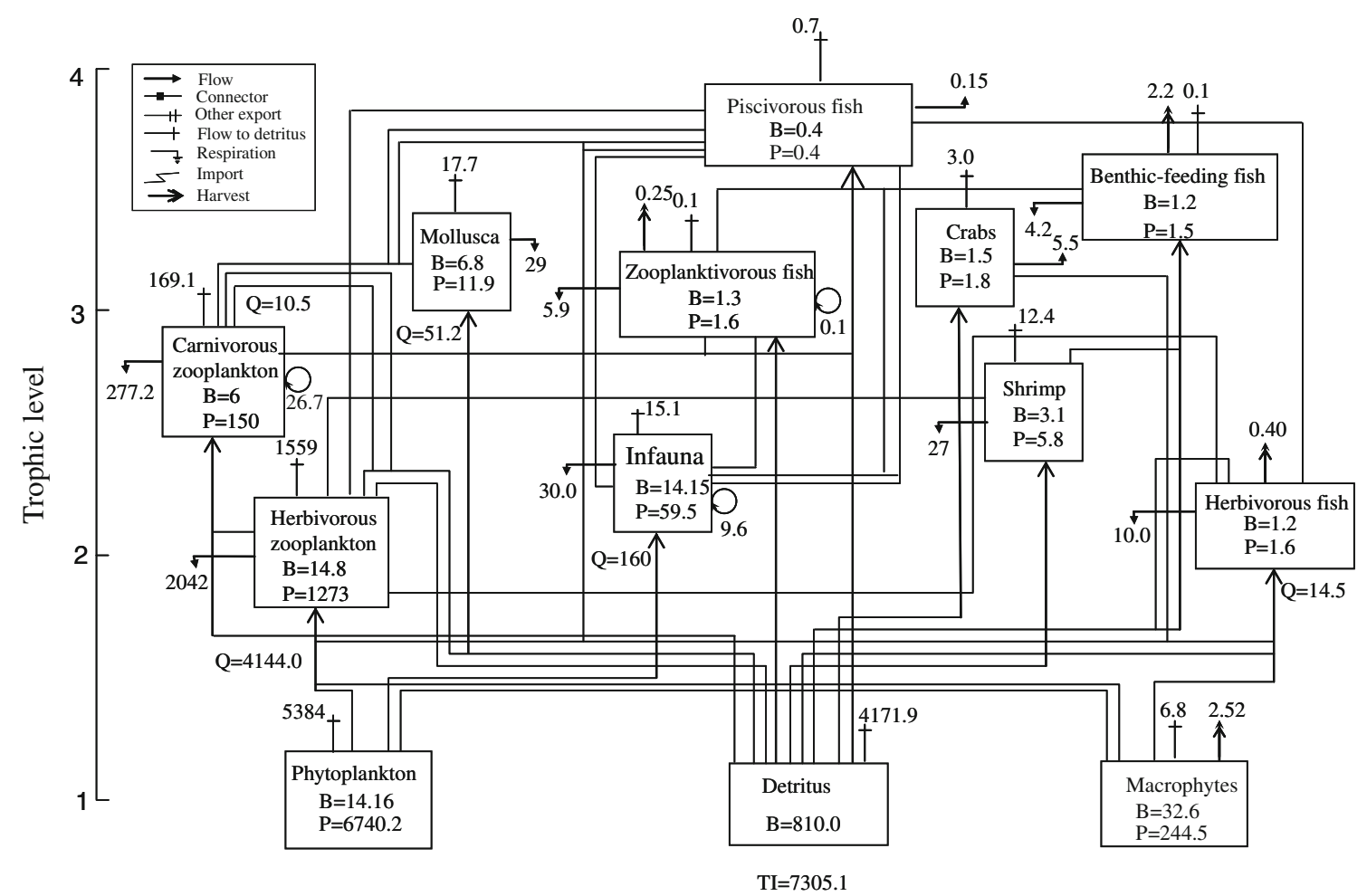

Fig. 2 Chart of trophic flow in the large-scale sea area enclosure in northern Hangzhou Bay. All flows were expressed in $\mathrm{t} \mathrm{km}^{-2} \mathrm{year}^{-1}$. Boxes are placed on the $Y$-axis according to trophic level; the size of each is proportional to biomass. $B$ biomass, $P$ Production, and $Q$ consumption 
Table 4 Relative flows of each group by trophic level for the artificial ecosystem

\begin{tabular}{|c|c|c|c|c|c|}
\hline Group names & I & II & III & IV & $\mathrm{V}$ \\
\hline 1 Phytoplankton & 1.000 & & & & \\
\hline 2 Macrophytes & 1.000 & & & & \\
\hline 3 Herbivorous zooplankton & & 1.000 & & & \\
\hline 4 Carnivorous zooplankton & & 0.211 & 0.879 & & \\
\hline 5 Infauna & & 0.745 & 0.146 & 0.109 & \\
\hline 6 Mollusca & & 0.330 & 0.343 & 0.306 & 0.022 \\
\hline 7 Shrimp & & 0.400 & 0.285 & 0.298 & 0.016 \\
\hline 8 Crabs & & 0.100 & 0.352 & 0.417 & 0.123 \\
\hline 9 Herbivorous fish & & 0.910 & 0.09 & & \\
\hline 10 Zooplanktivorous fish & & 0.303 & 0.308 & 0.372 & 0.124 \\
\hline 11 Benthic-feeding fish & & 0.340 & 0.320 & 0.168 & 0.354 \\
\hline 12 Piscivorous fish & & & 0.467 & 0.256 & 0.217 \\
\hline 13 Detritus & 1.000 & & & & \\
\hline
\end{tabular}

was the most important fishery species in terms of biomass in the artificial ecosystem.

\section{Pathway flows}

The transfer efficiency of matter is the ratio between the sum of the exports and flow predated by the next level and the throughput on the trophic level. The efficiencies of flows originating from primary producers, form detritus and from combined flows are summarized in Fig. 3. The artificial system in northern Hangzhou Bay consisted of five main aggregated trophic levels (from level I to V). Transfer efficiencies declined gradually from trophic levels III (10.7\%), IV (8.4\%) to $\mathrm{V}(7.3 \%)$. We obtained a mean transfer efficiency of $9.8 \%$ from detritus and $9.4 \%$ from primary producers within the ecosystem; therefore, the average trophic transfer efficiency for the system as a whole was $9.5 \%$ (Fig. 3).

Mixed trophic impacts (MTI) and keystone species

The MTI analysis for the artificial system indicated that an increase in low effective trophic levels such as trophic detritus and macrophytes has positive impacts on the largest number of consumer groups through their direct and indirect consumption. Carnivorous zooplankton had strong negative impact on the herbivorous zooplankton and on itself (Fig. 4). However, herbivorous zooplankton biomass has a moderately positive impact on zooplanktivorous fish, crabs, and shrimps since they feed largely on herbivorous zooplankton. The MTI analysis predicted that an increase in biomass of benthic-feeding fish would have a moderate or slight negative effect on crustacean (crabs and shrimps). This is because benthic-feeding fish feed largely on detritus and may be regarded as competitors for the same food source.

It is important to indentify keystone species to get further insight in the ecosystem structure. Figure 5 shows the keystoneness of the function groups in the artificial system. The keystoneness index estimated allows ranking the group by decreasing keystoneness. The keystone species are those groups with proposed index values close to or greater than zero. Herbivorous zooplankton have high keystoneness and ranked first, while top predators, benthic-feeding fish and piscivorous fish ranked second and third, respectively, in terms of overall effects and keystoneness in this system.

\section{Ecosystem analysis and indicators}

The size of system flows, such as consumption, export, respiratory flows, flows to detritus, system throughput, and production, are given in Table 5.

The total system throughput of $19,323 \mathrm{t} \mathrm{km}^{-2} \mathrm{year}^{-1}$, $26.8 \%$ was due to consumption $\left(5,191.522 \mathrm{t} \mathrm{km}^{-2}\right.$ year $\left.^{-1}\right)$ and $13.7 \%$ to respiratory process $\left(2,646.646 \mathrm{t} \mathrm{km}^{-2} \mathrm{y}^{-1}\right)$; $38.1 \%$ originated in backflows to detritus $(7,345.421$ $\mathrm{t} \mathrm{km}^{-2}$ year $\left.^{-1}\right)$ and $21.4 \%$ to export $\left(4,139.154 \mathrm{t} \mathrm{km}^{-2}\right.$ year $\left.^{-1}\right)$. The sum of all production was $8,294 \mathrm{t} \mathrm{km}^{-2} \mathrm{y}^{-1}$. The ratio of total primary production to total respiration was 2.56 and the ratio of total primary production to total biomass was 69.25. The Finn's cycling index (FCI) and the mean path length (FML) were 0.25 and 2.17 , respectively, in the system. The fisheries mean trophic level (1.52) is very low and reflects the fact that over $70 \%$ of the catch
Fig. 3 Flow network of organic matter and transfer efficiencies (\%) from each trophic level for the artificial ecosystem model. Flows from primary producers $(P P)$ and from detritus $(D)$ and flows out of the tops of boxes represent export, and flows out of the bottoms represent respiration

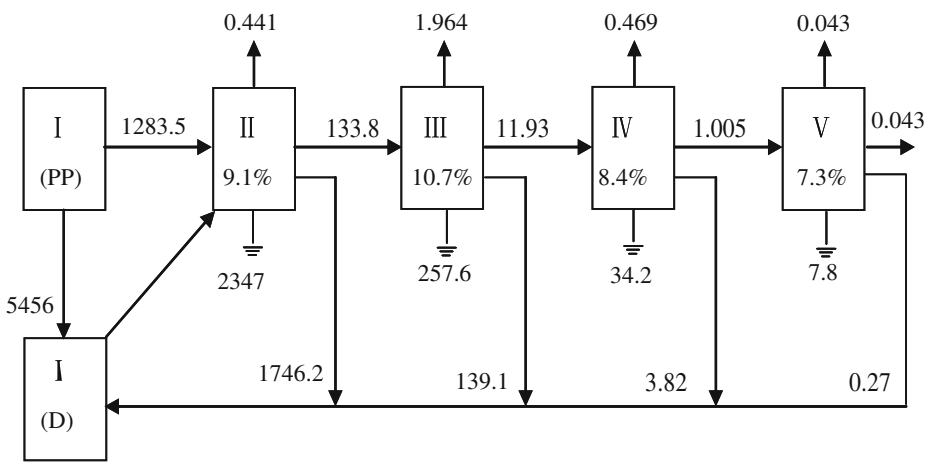

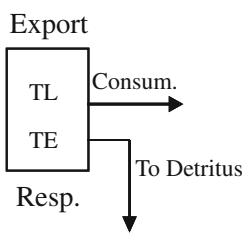




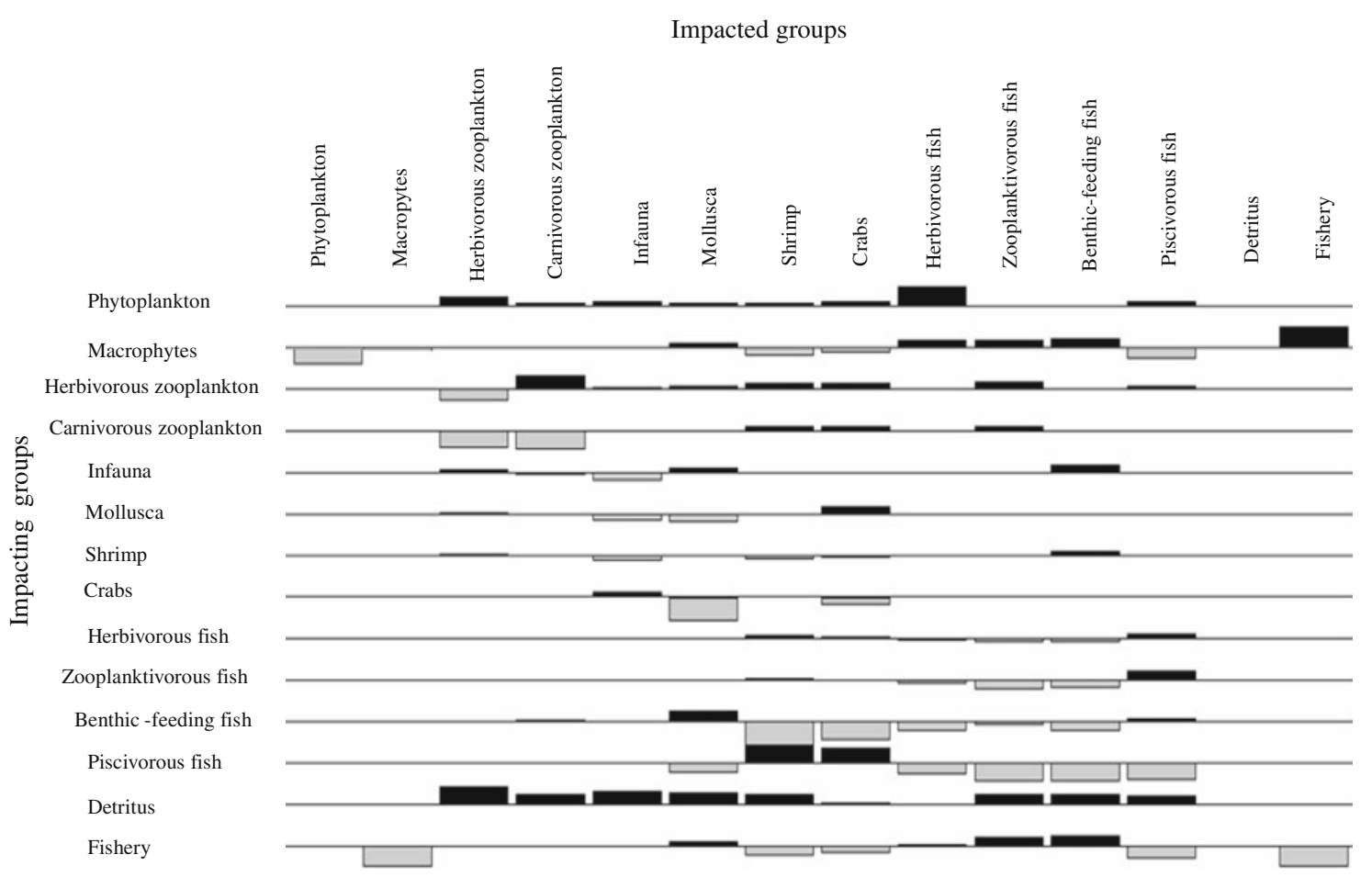

Fig. 4 Mixed trophic impacts of large-scale sea area enclosure in northern Hangzhou Bay. The magnitude of the impact is represented by shaded rectangles above (positive impacts) and below (negative impacts) the horizontal lines. Impacts are relative and comparable among groups

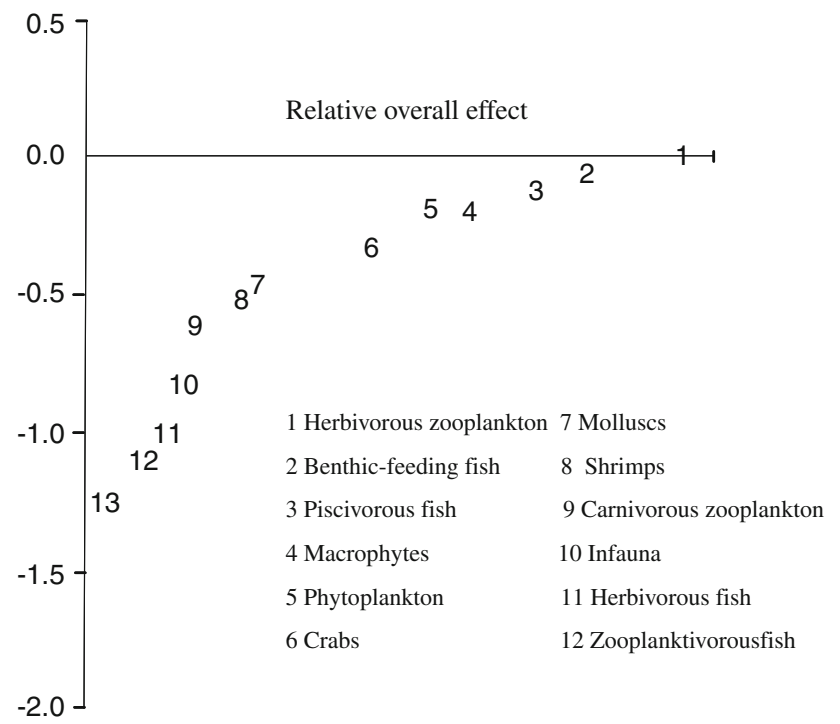

Fig. 5 Keystoneness index $\left(\mathrm{KS}_{i}\right)$ and relative overall effect $\left(\varepsilon_{i}\right)$ for the function groups in artificial ecosystem

coming from the macrophytes. Primary production required (PPR) for current total catch from the area is $2.8 \mathrm{t}$ per $\mathrm{km}^{2}$, which is equivalent to about $0.04 \%$ (Table 5). The ratio of total biomass to total flows into detritus (TB/ TDET), which indicates how much of the energy is transformed into organic material, is 0.013 in the system.
Simulation of impacts of fishing

Changes in biomass of selected species in response to varying fishing rate were simulated over a 10 -year period (Fig. 6a, b). The result of scenario 1 suggested that if the current low fishing mortality was maintained in this system, the biomass of piscivorous fish show a small increase, in particular in the first 4 years, while other selected groups keep stabilize during the simulation period (Fig. 6a). When modeled fishing effort reached twofold its current fishing rate, the biomass of piscivorous fish would rapid decreases to $70 \%$ lower than the initial biomass. However, the other fish groups would increase in varies degrees. The zooplantivorous fish would increase over $100 \%$. In contrast to the fish groups, biomass of the macrophytes would be relatively stabile during the simulation period (Fig. 6b).

Uncertainty and sensitivity analyses

The precision of Ecopath model output is comparable to that of the input data (Essington 2007). The pedigree index (0.61) is in the upper part of the range (0.16-0.68) of 150 Ecopath models (Morissette et al. 2006), indicating that the parameter values of the model were based on reliable sources and the model is of acceptable quality (Christensen et al. 2000). 
Table 5 Summary statistics for the artificial ecosystem model

\begin{tabular}{lrl}
\hline Attribute parameters & Value & Unit \\
\hline Total consumption (CT) & $5,191.52$ & $\mathrm{t} \mathrm{km}^{-2} \mathrm{year}^{-1}$ \\
Total exports (TEX) & $4,139.15$ & $\mathrm{t} \mathrm{km}^{-2} \mathrm{year}^{-1}$ \\
Total respiratory flows (TR) & $2,646.65$ & $\mathrm{t} \mathrm{km}^{-2} \mathrm{year}^{-1}$ \\
Total flows into detritus (TDET) & $7,345.42$ & $\mathrm{t} \mathrm{km}^{-2} \mathrm{year}^{-1}$ \\
Total system throughput (T) & $19,323.00$ & $\mathrm{t} \mathrm{km}^{-2} \mathrm{year}^{-1}$ \\
Total production (TP) & $8,294.00$ & $\mathrm{t} \mathrm{km}^{-2} \mathrm{year}^{-1}$ \\
Calculated total net primary production & $6,785.80$ & $\mathrm{t} \mathrm{km}^{-2} \mathrm{year}^{-1}$ \\
$\quad$ TPP) & & \\
Total biomass (TB), excluding detritus & 97.99 & $\mathrm{t} \mathrm{km}^{-2}$ \\
Mean trophic level of the catch & 1.52 & \\
Calculated total net primary production/ & 2.56 & \\
total respiration & & \\
Net system production (NSP) & $4,139.15$ & $\mathrm{t} \mathrm{km}^{-2}$ year $^{-1}$ \\
Total primary production/total biomass & 69.25 & \\
Finn Cycling Index (FCI) & 25.00 & \\
Finn's mean path length (FML) & 2.174 \\
Ascendancy (A) & 0.315 \\
System overhead (O) & 0.69 \\
Connectance index (CI) & 0.31 & \\
System omnivory index (SOI) & 0.35 & \\
\hline
\end{tabular}

The sensitivity analysis revealed that the relationship between changes in input parameters and the affected parameters were nearly linear; hence, only the effects of a $50 \%$ increase in one parameter were considered. The estimated parameters were sensitive to the input parameters within a functional group, while the outputs were generally robust to parameters from other functional groups (Appendix A-Electronic supplementary material). For instance, when one input parameter of a functional group was increased by $50 \%$, the output parameters of that group varied from +35.4 to $-33.3 \%$. This was expected as the input parameters of a functional group (e.g., $P / B, Q / B, E E$ ) are tightly linked with each other. Excluding this withingroup effect, the estimated parameters were reasonably robust to changes in input parameter values of other functional groups in the artificial ecosystem model. A 50\% change in input parameter values led to, on average, a $15 \%$ change in the output values. The most sensitive sets of parameters were the effect of the assumed EE of herbivorous zooplankton on the estimated EEs of phytoplankton, macrophytes, herbivorous zooplankton, carnivorous zooplankton, and herbivorous fish. Generally, changes in the consumption-biomass ratios had lower impacts on the estimated parameters.

\section{Discussion}

The Ecopath model was used to construct a mass-balance model, which is considered to be the first step in summarizing ecological and biological information in a coherent framework through trophic networks in the ecosystem. As previously mentioned, few studies of ecosystem properties have focused on artificial coastal ecosystems in the world, particularly in the East China Sea (Yan et al. 2008). A comparison with other coastal ecosystems (Wolff 1994;

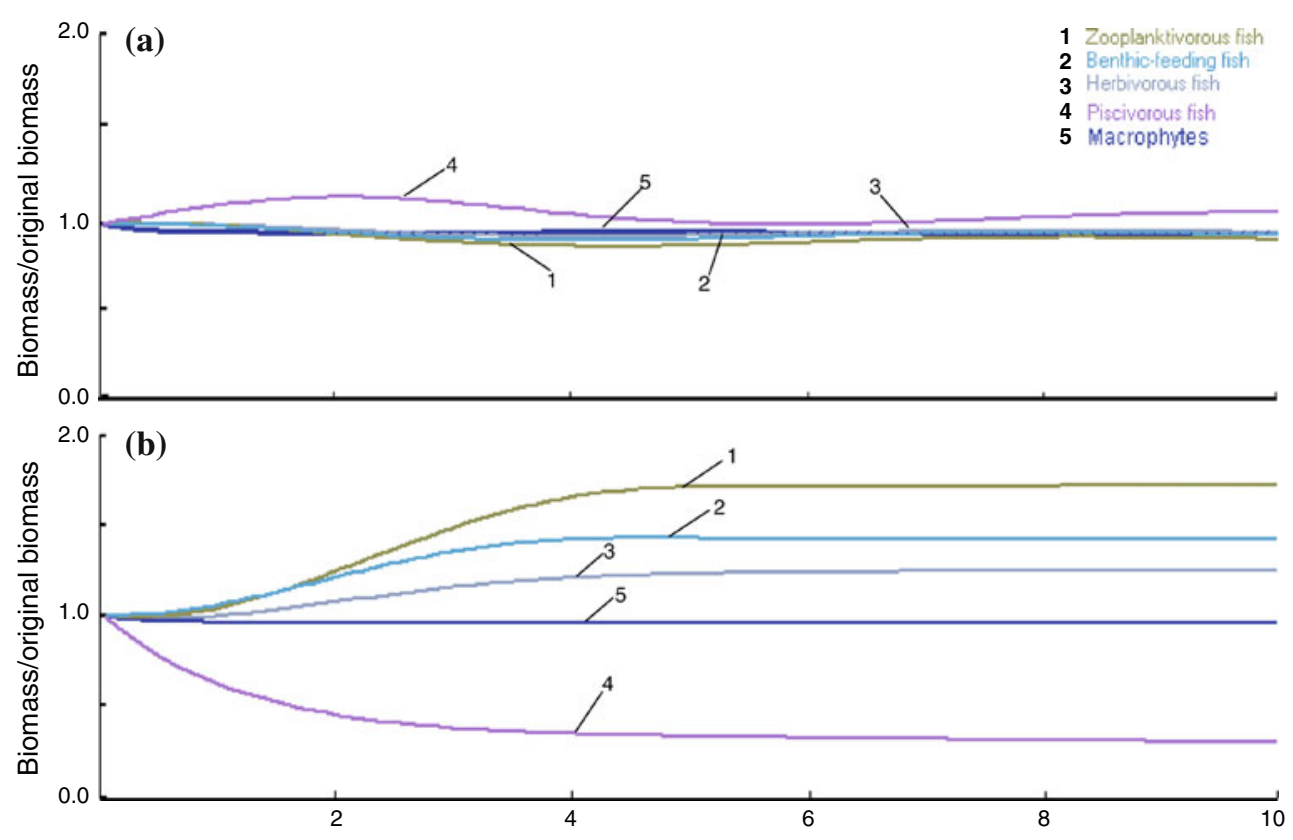

Fig. 6 Simulated changes in biomass of selected groups in response to different fishing mortality. a Fishing mortality at current level; $\mathbf{b}$ fishing mortality increased twofold of the current fishing mortality 
Table 6 Comparison of ecosystem attributes in Hangzhou Bay, Shensi Bay, Kuosheng Bay, and Tongoy Bay

\begin{tabular}{|c|c|c|c|c|c|}
\hline Attribute parameters & $\begin{array}{l}\text { Artificial ecosystem } \\
\text { (this study) }\end{array}$ & $\begin{array}{l}\text { Shensi Bay } \\
\text { (Li et al. 2007) }\end{array}$ & $\begin{array}{l}\text { Tongoy Bay } \\
\text { (Wolff 1994) }\end{array}$ & $\begin{array}{l}\text { Kuosheng Bay } \\
\text { (Lin et al. 2004) }\end{array}$ & Unit \\
\hline Total consumption $(\mathrm{CT})$ & $5,191.52$ & $2,249.94$ & $7,669.00$ & $14,701.00$ & $\mathrm{t} \mathrm{km}^{-2}$ year $^{-1}$ \\
\hline Total respiratory flows (TR) & $2,646.65$ & $1,249.06$ & $4,021.00$ & $6,328.00$ & $\mathrm{t} \mathrm{km}^{-2}$ year $^{-1}$ \\
\hline Total flows into detritus (TDET) & $7,345.42$ & $1,179.14$ & $6,040.00$ & $8,281.00$ & $\mathrm{t} \mathrm{km}^{-2}$ year $^{-1}$ \\
\hline Total system throughput $(\mathrm{T})$ & $19,323.00$ & $5,160.00$ & $20,835.00$ & $29,692.00$ & $\mathrm{t} \mathrm{km}^{-2}$ year $^{-1}$ \\
\hline Calculated total net primary production (TPP) & $6,785.80$ & $1,730.16$ & $7,125.00$ & $6,710.00$ & $\mathrm{t} \mathrm{km}^{-2}$ year $^{-1}$ \\
\hline Total biomass (TB), excluding detritus & 97.99 & 61.773 & 263.00 & 167.00 & $\mathrm{t} \mathrm{km}^{-2}$ \\
\hline TPP/TR & 2.56 & 1.38 & 1.77 & 1.06 & \\
\hline TB/TDET & 0.013 & 0.052 & 0.044 & 0.020 & \\
\hline Finn Cycling Index (FCI) & 25.00 & 9.73 & 10.10 & 32.00 & \\
\hline Finn's mean path length (FML) & 2.17 & 3.69 & 4.90 & 4.40 & \\
\hline Ascendancy (A) & 0.31 & 0.44 & 0.44 & 0.48 & \\
\hline System overhead $(\mathrm{O})$ & 0.69 & 0.56 & 0.56 & 0.52 & \\
\hline
\end{tabular}

Lin et al. 2004; Li et al. 2007) using the results from network analysis would be helpful in characterizing the status of the artificial ecosystem in northern Hangzhou Bay (Table 6).

Total system throughput (sum of consumption, exports, respiratory flows, and flows into detritus) of the artificial ecosystem is lower than that of the tropical coastal ecosystem Kuosheng Bay, Taiwan and Tongoy Bay, Chile, but higher than that of Shensi Bay, a temperate coastal system in the East China Sea (Table 6). The mean transfer efficiency for this ecosystem is $9.5 \%$, slightly lower than the $10 \%$ assumed by Lindeman (1942), and which is shown to be a good estimate of the average transfer efficiency in aquatic ecosystems (Pauly and Christensen 1995). The computed mean transfer efficiency between trophic levels $(9.5 \%)$ is slightly lower than the $15 \%$ value given by Ryther (1969) for coastal zones. In fact, about $43 \%$ of the system matter flow originated from primary producers; the other $57 \%$ was from detritus, indicating that the artificial ecosystem was more dependent on the detritus pool than on primary producers to generate total system throughput. This is because only half of primary production of phytoplankton and macrophytes was directly predated, and the other half were not immediately used by the upper trophic levels and thus flowed into the detrital pool.

The sum of all consumption (CT), total net primary production (TPP), total biomass (TB), total primary production to total respiration ratio (TPP/TR), and Finn's cycling index (FCI) are also comparable with the ratios reported from other temperate coastal ecosystems such as Shensi Bay (Li et al. 2007), Tongoy Bay (Wolff 1994), and Kuosheng Bay (Lin et al. 2004). The gross efficiency (fishery catch/net system production ratio) is only $0.026 \%$, much lower than those reported in China's coastal ecosystem, Bohai Bay (Tong et al. 2000) and Beibu Gulf
(Chen et al. 2008). This suggests that the fishing pressure in the system is comparatively low.

According to Odum (1971), the ratio of TPP/TR is a very important measure of system maturity. A ratio greater than 1 is expected in the early developmental stages of an ecosystem, while in mature systems, it should approach 1 . The value of TPP/TR obtained in this study is obviously higher than 1, and much higher than the autotrophic model in Kuosheng Bay, suggesting that the artificial ecosystem is still developing. It means that more organic matter was produced than consumed in the system. FCI gives the proportion of flow in a system that is recycled compared to total system throughput (Table 6). The value of $25 \%$ for this system is lower than that for the typical temperate coastal system (Kuosheng Bay), but much higher than that of Shensi Bay and Tongoy Bay. Finn's mean path length (FML), which measures the mean number of groups that a unit of flux will experience from its entry into the system until it leaves the system, was low (2.17) when compared with the range (3.688-4.900) reported for the three coastal systems mentioned earlier. The results indicate that while a small proportion of matter was cycled through detrital pathways, it was retained within the system for a certain period by being consumed and transferred up the food web. $\mathrm{CI}$ and SOI are also correlated with system maturity since the food chain is expected to change from linear to weblike as the system matures (Odum 1971). For the system, the values of CI and SOI are 031 and 0.35 , respectively, suggesting a simplification of the food web, and a system that is not fully mature and stable.

The MTI routine analysis shows that fish have only negative impacts on the other compartments due to their role as predators and competitors in the system. Feeding by compartments at high trophic levels with relatively high consumption, such as herbivorous zooplankton, is expected 
to exert significant control on prey populations through predation, that is, 'top-down' control (Carpenter et al. 1985). Compartments as lower trophic levels, particularly detritus and macrophytes, impact positively on a large number of other compartments, signifying their role as a food source and their impact on the supplies of food resources to consumers, that is, they have high potential for 'bottom-up' (McQueen et al. 1986). The importance of detritus in the system is again clearly seen from the mixed trophic impacts, where detritus has a positive impact on all consumers as well as on the fishery.

Keystone species relatively low biomass species with a structuring role in the food web. These species have strong influence on the abundance of other species and ecosystem dynamics in a manner disproportionate to their own abundance (Power et al. 1996; Libralato et al. 2006). Generally, marine mammals often have high keystoneness, and rank first (Alaska gyre, Azores, Newfoundland, Norwegian Barents Sea models) or second (Easter tropic Pacific models, Floreana, Georgia Strait, Newfoundland 1985-1987) in many models, while in coastal and semienclosed marine environments (Bolinao reef, Chesapeake Bay, Georgia Strait, Gulf of Thailand), the zooplankton group has high keystoneness (Libralato et al. 2006). In the artificial ecosystem in northern Hangzhou Bay, the herbivorous zooplankton was identified as keystone species. Considering the herbivorous zooplankton in the intermediate position of the trophic web can be seen Fig. 2, which indicates that this intermediate functional group contributed to the tropical control of wasp-waist in this system.

The artificial system model estimate of $25.8 \%$ PPR for harvest of all groups is similar to the average value of PPR of $24-35.3 \%$ for commercial fisheries in non-trophic shelf systems (Pauly and Christensen 1995). The mean trophic level of the catch $\left(\mathrm{TL}_{c}=1.52\right)$ in this system is lower than for most other ecosystem (Pauly et al. 1998). The lower biomass and catch of some fish groups in this model may account for absence of higher trophic levels, the low ecotrophic efficiency of some fish groups, and low fishery efficiency of the system. The coastal ecosystem's food web is dominated by the detrital pathway as in many other estuarine systems (Day et al. 1989), with benthic invertebrates playing a significant role in transferring energy from the detritus to higher trophic levels. Odum (1969) suggested that as systems mature, they become more dependent on detritivory than herbivory. Considering the artificial is a typical coastal system with the detrital pathway playing a significantly role in transferring energy from detritus to higher trophic levels, the index TB/TDET is a more suitable attribute to indicate the ecosystem features. In this artificial system, the value of TB/TDET is low compared to Kuosheng Bay, Tongoy Bay, and Shensi Bay ecosystems, in which TB/TDET ranged from 0.020 to
0.052 and was remarkably lower than 1 also. Therefore, all these parameters (TPP/TR, FCI, FML, SOI, CI, and TB/ TDET) of ecosystem maturity suggest that the artificial system is not mature and stable in our study.

The exploration of varying fishing scenarios needs to be made from the point of view of not only direct effects of fishing but also indirect effects of fishing on non-target species. For this purpose, Ecosim could provide a good insight into the ecosystem impacts of fisheries exploitation (Christensen et al. 2000). In our Ecosim simulations, the most function groups would be slightly increase when the fishing mortality maintains the existing level due to the current fishing pressure is relatively low. As expected, under high fishing mortality, such as in scenario 2, the top predator has the most outstanding declines due to their low $P / B$ ration and life strategies, in contrast to other fish groups would increased rapidly as the consequence of decreased predation. Generally, simulation of possible impacts of fishing indicates that high fishing mortality would actually have long-term negative consequences for the biomass of large demersal fishes (piscivorous fish) in particular.

\section{Conclusions}

This is the first trophic model of a large-scale artificial ecosystem enclosure in China. It also provides some useful insights into the characteristics of the system, and the artificial ecosystem model shows that the trophic structure functioning behaved like a typical coastal ecosystem. This artificial ecosystem possesses great amount of reserve energy $(\mathrm{O})$, showing that it is a system that can support unpredictable disturbance. These observations could be made use of in other tropical coastal ecosystems to assess the impact of environmental management measures. In general terms, these results are only preliminary, and further studies are required to verify the impacts of macrophytes aquaculture and the impacts of fishing in the artificial ecosystem. Furthermore, we suggest that the last point must being examined in future works to increase and improve the foundations that allow more precise evaluations of the health of the system, and for obtaining better measures about biological conservation and enhancement of the artificial ecosystem.

Acknowledgments The authors thank the CDMCJS for the use of the data and unpublished information incorporated in this study. This publication was partly funded by the Bioremediation Engineering Program of City Beach in Jinshan District, Shanghai; the Special Project of Social Commonwealth Research of National Institute (No. 2010ZD01); China Postdoctoral Science Foundation (No. 20090460825); Key Laboratory of Mariculture, Ecology and Quality Control, Ministry of Agriculture, South China Sea Fisheries Research 
Institute, Chinese Academy of Fishery Sciences (No. 2008B1204); the LMB, LAMB and LMM in South China Sea Institute of Oceanology, Chinese Academy of Sciences (No. LMB091009). Furthermore, we are grateful to the anonymous reviewers for their constructive comments.

\section{References}

Ahlstrom EH, Thrailkill JR (1960) Plankton volume loss with time of preservation. CalCOFI Rep 9:57-73

Allen KR (1971) Relation between production and biomass. J Fish Res Board Can 28:1573-1581

Baird D, Ulanowicz RE (1989) The seasonal dynamics of the Chesapeake Bay ecosystem. Ecol Monogr 59:329-364

Beverton RJH, Holt SJ (1957) On the dynamics of exploited fish populations. Chapman \& Hall, London, $533 \mathrm{pp}$

Buchary EA, Cheung WL, Sumaila UR, Pitcher TJ (2003) Back to the future: a paradigm shift for restoring Hong Kong's marine ecosystem. Am Fish Soc Symp 38:727-746

Carpenter SR, Kitchell JF, Hodgson JR (1985) Cascading trophic interactions and lake productivity. Bioscience 35:634-639

Chen ZZ, Qiu YS, Jia XP, Xu SN (2008) Using an ecosystem modeling approach to explore possible ecosystem impacts of fishing in the Beibu Gulf, northern South China Sea. Ecosystems $11: 1318-1334$

Christensen V (1995) Ecosystem maturity-towards quantification. Ecol Model 77:3-32

Christensen V, Pauly D (eds) (1993) Trophic models of aquatic ecosystems. In: ICLARM conference proceedings 26:390

Christensen V, Walters CJ (2004) Ecopath with Ecosim: methods, capabilities, and limitation. Ecol Model 172:109-139

Christensen V, Walters CJ, Pauly D (2000) ECOPATH with ECOSIM, version 5, Help system ${ }^{\odot}$. University of British Columbia, Fisheries Centre/ICLARM, Vancouver/Penang

Christian RR, Forés E, Comin F, Viaroli P, Naldi M, Ferrari I (1996) Nitrogen cycling networks of coastal ecosystems: influence of trophic status and primary producer form. Ecol Model 87:111-129

Dalsgaard JPT, Oficial RT (1997) A quantitative approach for assessing the productive performance and ecological contributions of smallholder farms. Agric Syst 55:503-533

Day JW, Hall CAS, Kemp WM, Yáez-Arancibia A (1989) Estuarine ecology. Wiley, New York

De Jonge VN, Elliott M, Orive E (2002) Causes, historical development, effects and future challenges of a common environmental problem: eutrophication. Hydrobiologia 475(476): 1-19

Erftemeijer PLA, Osinga R, Mars AE (1993) Primary production of seagrass beds in South Sulawesi (Indonesia): a comparison of habitats, methods and species. Aquat Bot 46:67-90

Essington TE (2007) Evaluating the sensitivity of a trophic massbalance model (Ecopath) to imprecise data inputs. Can J Fish Aquat Sci 64:628-637

Finn JT (1976) Measures of ecosystem structure and function derived from analysis of flows. J Theor Biol 56:363-380

Froese R, Pauly D (eds) (2004) Fish base. World Wide Web electronic publication. http://www.fishbase.org, version (06/2004)

Gayanilo FC Jr, Sparre P, Pauly D (1996) The FAO-ICLARM Fish Stock Assessment Tools (FiSAT) user guide. FAO Computerized Information Series (Fisheries). No 7. FAO of the United Nations, Rome, $180 \mathrm{pp}$

He PM, Xu SN, Zhang HY, Wen SS, Dai YJ, Lin SJ, Yarish C (2008) Bioremediation efficiency in the removal of dissolved inorganic nutrients by the red seaweed, Porphyra yezoensis, cultivated in the open sea. Wat Res 42:1281-1289

Leontief W (1951) The structure of American economy, 1919-1939: an empirical application of equilibrium analysis. Oxford University Press, New York

Li YG, Wang ZH, Zhang SY (2007) A preliminary approach on the ecosystem model of the artificial reef in Shengsi. Mar Fish 29:226-234 (in Chinese, with English abstract)

Libralato S, Christensen V, Pauly D (2006) A method for identifying keystone species in food web models. Ecol Model 195:153-171

Lin HJ, Shao KT, Kuo SR, Hsieh HL, Wong SL, Chen IM, Lo WT, Hung JJ (1999) A trophic model of a sandy barrier lagoon at Chiku in southwestern Taiwan. Estuar Coast Shelf S 48:575-588

Lin HJ, Shao KT, Hwang JS, Lo WT, Cheng IJ, Lee LH (2004) A trophic model for Kuosheng Bay in northern Taiwan. J Mar Sci Tech 12:424-432

Lindeman RL (1942) The trophic-dynamic aspect of ecology. Ecology 23:399-417

Liu ZL, Ning XR, Cai LM (2001) Primary productivity and standing stock of the phytoplankton in the Hangzhou Bay to the Zhoushan Fishing Ground during autumn. Acta Oceanol Sinica 23:48-53

MacLennan DN, Simmonds EJ (1992) Fisheries acoustics. Chapman \& Hall, London, p 325

Manickchand-Heileman S, Mendoza-Hill J, Kong AL, Arocha F (2004) A trophic model for exploring possible ecosystem impacts of fishing in the Gulf of Paria, between Venezuela and Trinidad. Ecol Model 172:307-322

McQueen DG, Post JR, Mills EL (1986) Trophic relationships in freshwater pelagic ecosystems. Can J Fish Aquat Sci 43:1571-1581

Morissette L, Hammill MO, Savenkoff C (2006) The trophic role of marine mammals in the northern Gulf of St Lawrence. Mar Mammal Sci 22:74-103

Neori A, Chopin T, Troell M, Buschmann AH, Kraemer GP, Halling C, Shpigel M, Yarish C (2004) Integrated aquaculture: rationale, evolution and state of the art emphasizing seaweed biofiltration in modern mariculture. Aquaculture 231:361-391

Odum EP (1969) The strategy of ecosystem development. Science $164: 262-270$

Odum EP (1971) Fundamental of ecology. Saunders, Philadelphia, p 574

Odum WE, Heald EJ (1975) The detritus-based food web of an estuarine mangrove community. In: Cronin LE (ed) Estuarine research. Academic Press, New York, pp 265-286

Palomares MLD, Pauly D (1998) Predicting food consumption of fish populations as functions of mortality, food type, morphometrics, temperature and salinity. Mar Freshw Res 49:447-453

Parsons TR, Maita Y, Lalli CM (1984) A manual of chemical and biological methods for seawater analysis. Pergamon Press, Oxford, pp 3-122

Pauly D, Christensen V (1995) Primary production required to sustain global fisheries. Nature 374:255-257

Pauly D, Christensen V, Dalsgaard J, Froese R, Torres FC Jr (1998) Fishing down marine food webs. Science 279:860-863

Power ME, Tilman D, Estes JA, Menge BA, Bond WJ, Scott Mills L, Daily G, Castilla JC, Lubchenco J, Paine RT (1996) Challenges in the quest for keystones. Bioscience 46:610-620

Ryther JH (1969) Photosynthesis and fish production in the sea. Science 166:72-76

SEPAC (State Environmental Protection Administration of China) (2002) Seawater quality standard. Science Press, Beijing, pp 132-136 (in Chinese)

Shen XQ, Yuan Q, Wang YL, Jiang M (2003) Study on assessment of eco-environmental quality in fishery waters near the Changjiang River estuary and Hangzhou Bay. J Fish China 27(suppl):76-81 (in Chinese, with English abstract) 
State Oceanic Administration of China (SOAC) (2005) The China Marine Environment Bulletin in 2004. Available at http://www. soa.gov.cn/hygb/2004hyhj (in Chinese)

Tong L, Tang Q, Pauly D (2000) A preliminary approach on massbalance ecopath model of the Bohai Sea. Chin J Appl Ecol 11:435-440 (in Chinese, with English abstract)

Troell M, Halling C, Neori A, Chopin T, Buschmann AH, Kautsky N, Yarish C (2003) Integrated mariculture: asking the right questions. Aquaculture 226:69-90

Ulanowicz RE (1986) Growth and development: ecosystems phenomenology. Springer, New York

Ulanowicz RE, Puccia CJ (1990) Mixed trophic impacts in ecosystems. Coenoses 5:7-16

Vega-Cendejas ME (2003) Trophic dynamics of a mangrove ecosystem in Celestun Lagoon, Yucatan Peninsula, Mexico. Fish Centre Res Rep 11:237-243

Walters C, Christensen V, Pauly D (1997) Structuring dynamic models of exploited ecosystems from trophic mass-balance assessments. Rev Fish Biol Fish 7:139-172

Walters C, Pauly D, Christensen V, Kitchell JF (2000) Representing density dependent consequences of life history strategies in aquatic ecosystems: Ecosim II. Ecosystems 3:70-83
Wolff M (1994) A trophic model for Tongoy Bay-a system exposed to suspended scallop culture (Northern Chile). J Exp Mar Biol Ecol 182:149-168

Xu SN (2008) The bioremediation of eutrophic coastal sea areas by seaweed cultivation. Ph.D. Dissertation, Shanghai Ocean University

$\mathrm{Xu} \mathrm{SN}, \mathrm{He} \mathrm{PM}$ (2006) Analysis of phenomena for frequent occurrence of red tides and bioremediation by seaweed cultivation. J Fish China 30:554-561 (in Chinese, with English abstract)

Yan L, Cheng TX, Ye HR, Zheng XY, Kong HN (2008) Study on the purification of landscape water by multi-stage artificial ecosystem. Technol Water Treat 34:26-30

Yuan D, Yi Y, Yakupitiyage A, Fitzimmons K, Diana JS (2010) Effects of addition of red tilapia (Oreochromis spp.) at different densities and sizes on production, water quality and nutrient recovery of intensive culture of white shrimp (Litopenaeus vannamei) in cement tanks. Aquaculture 298:226-238

Zhang J, He Z (1991) Handbook of Investigation on the Fishery and Natural Resources of Inland Waters. Agriculture Press, Beijing, pp 12-169 (in Chinese) 